\title{
Role of Bioelectronics in the Quest of Inhabiting other Planets
}

\section{Madhu MSK*}

Electrical and Computer Engineering, University of Wisconsin-Madison, Fremont, California, USA

Till date the data obtained from various robotic/un-manned expeditions have provided humankind with promising data that there are planets beyond earth where life is possible. Mars being our best bet. Sensor data showing possibility of $\mathrm{H}_{2} \mathrm{O}$ in frozen form beneath the Mars surface has lured more and more explorers/optimists such as Elon Musk, Jeff Bezos and several others to join the rat race for colonizing the planet. However, no evidence of any form of biological species has been found so far!

Bioelectronics are not only critical in understanding the biological feasibility of other planets, but even more important to monitor health and avoid bio/chemical hazards for human explorers (and optimistically human inhabitants). More importantly, to avoid any cross-contamination and misrepresentation of data, it is required that these bioelectronics devices be positioned for in-field detection and analysis rather than analyzing samples after relocating them to earth's laboratory. Early settlers, explorers are inevitable to use these devices. Finding a large living body may sound too fictional and sci-fi, but a more practical approach would be to detect extraterrestrial life by detecting biomolecules such as lipids, proteins, nucleic acid etc.

Rezzonicco, Miles et al., Sexton et al., have recently (independently) showed that nanopore based biosensors allow detection and analysis up to single molecular level [1-3]. They also showed sequencing of biopolymers such as DNA/RNA, by quantifying the electrical current changes when the analyte flows through the nanopores [1]. This technology indicates its potential to detect biopolymers and genetic information carriers without the detailed information regarding their basic chemistry [1-3]. These biosensing devices being small scaled, portable and possibly automated makes them an ideal candidate for in-field search of extraterrestrial biospecies/biomolecules.

David Cullen (Cranfield's Biotechnology Centre) and Mark Sims (University of Leicester) have already developed several biomimetic sensors which are planned for several astrobiological applications and future planetary missions. His team has conducted research in detecting life forms in extreme conditions on earth such as glacial environments [4-6], volcanic beds etc. Their sensor consists of molecular imprinted polymers with cavities in it, which can fit a particular molecule which needs to be sensed [4-8].

Mark Sims and his team previously showed a cohesive approach for the detection of a wide range of biomolecules simultaneously. The sensing system abbreviated as SMILE (Specific Molecular Identification of Life Experiment) was sensitive enough to a range of targeted molecules [9]. This included electrical and optical approaches with imprinted polymers and antibodies as the sensing layers. This robust and compact bio sensing system functions as a "Life Marker Chip", which helps in the detection of several biological activities during planetary exploration [9].

With several space research agencies such as National Aeronautical Space Agency (NASA), European Space Agency (ESA), and recently Indian Space Research Organization (ISRO) coming forward with more innovations in exploring life out of earth's atmosphere and ways to aid human habitation on planets other than earth, it seems that detection of life form is certain to come true in the near future.

\section{References}

1. Rezzonico F (2014) Nanopore-based instruments as biosensors for future planetary missions. Astrobiology 14: 344-351.

2. Miles BN, Ivanov AP, Wilson KA, Doğan F, Japrung D, et al. (2013) Single molecule sensing with solid-state nanopores: novel materials, methods, and applications. Chem Soc Rev 42: 15-28.

3. Sexton LT, Horne LP, Martin CR (2007) Developing synthetic conical nanopores for biosensing applications. Mol Biosyst, pp: 667-685.

4. Cullen DC, Barnett MJ, Pawlett M, Wadham JL, Jackson M (2016) Demonstration of a multi-technique approach to assess glacial microbial populations in the field. Journal of Glaciology 62: 348-358.

5. Cullen DC, Barnett MJ, Wadham JL, Jackson M (2012) In-Field Implementation of a Recombinant Factor C Assay for the Detection of Lipopolysaccharide as a Biomarker of Extant Life within Glacial Environments. Biosensors 2: 83-100.

6. Cullen DC, Barnett MJ, Pearce DA (2012) Advances in the in-field detection of microorganisms in ice. Advances in Applied Microbiology 81: 133-167.

7. Amador ES, Cable ML, Chaudry N, Cullen T, Gentry D, et al. (2015) Synchronous in-field application of life-detection techniques in planetary analog missions. Planetary and Space Science 106: 1-10.

8. Payler SJ, Biddle JF, Coates AJ, Cousins CR, Cross RE, et al. (2016) Planetary science and exploration in the deep subsurface: results from the MINAR Program. International Journal of Astrobiology.

9. Sims MR, Cullen DC, Bannister NP, Grant WD, Henry O, et al. (2005) The Specific Molecular identification of Life Experiment (SMILE). Planetary and Space Science 53: 781-791.
*Corresponding author: Madhu MSK, Doctor of Philosophy (PhD), Electrical and Computer Engineering, University of Wisconsin-Madison, 2736 Pismo, Terrace, Fremont, California, USA, Tel: (318)243 916594538 ; E-mail: Madhu.Mutyala@lamresearch.com

Received March 28, 2017; Accepted March 29, 2017; Published March 31, 2017

Citation: Madhu MSK (2017) Role of Bioelectronics in the Quest of Inhabiting other Planets. J Biosens Bioelectron 8: e146. doi: 10.4172/2155-6210.1000e146

Copyright: (c) 2017 Madhu MSK. This is an open-access article distributed under the terms of the Creative Commons Attribution License, which permits unrestricted use, distribution, and reproduction in any medium, provided the original author and source are credited. 